\title{
Endoscopic injection therapy in bleeding peptic ulcers. Low mortality in a high risk population
}

\author{
JoAQUim BALANZÓ, MD, CÁNDID VillanUeVA, MD, JORGE C Espinós, MD, \\ Sergio SÁinz, MD, German Soriano, MD, Dolors GonzÁlez, MD, XAVIER Rius, MD, \\ Jorge PUIG LA CAlLE, MD, FACS, FranCisCo VIlaRdell, MD, FRCP, FACP
}

JBALANZó, C VillanUeVa, JC Espinós, et al. Endoscopic injection therapy in bleeding peptic ulcers. Low mortality in a high risk population. Can J Gastroenterol 1992;6(5):265-268. Endoscopic injection therapy was performed in 341 patients consecutively admitted with a bleeding peptic ulcer at high risk of further hemorrhage, assessed by the presence of active arterial bleeding or a nonbleeding visible vessel at emergency endoscopy. Initial hemostasis was achieved in 111 of 119 actively bleeding patients (93\%). Rebleeding occurred in 75 cases $(23 \%)$, at a mean interval of $53 \pm 52 \mathrm{~h}$. A second emergency injection was attempted in 36 therapeutic failures, and was successful in 20 $(55 \%)$. Emergency surgery was finally required in 52 patients (15\%). Overall mortality was $4.9 \%$. Major complications occurred in four patients $(1.2 \%$ ) (two perforations and two aspiration pneumonia); therefore, injection therapy is an effective and simple method for treating bleeding ulcers, achieving the initial control of hemorrhage in a majority of cases although the rate of further hemorrhage is not negligible and complications are not irrelevant.

Key Words: Bleeding peptic ulcer, Injection therapy, Therapeutic endoscopy

\section{Traitement d'ulcères gastro-duodénaux hémorragiques au} moyen d'une injection administrée par voie endoscopique. Faible taux de mortalité dans une population à risque élevé

RÉSUMÉ: Un traitement en injection par voie endoscopique a été administré à 341 patients consécutifs admis pour ulcère gastro-duodénal actif et à risque élevé à l'égard d'hémorragies subséquentes, tel qu'attesté par la présence d'une hémorragie artérielle active ou non à l'endoscopie d'urgence. Une hémostase initiale a été obtenue chez 111 des 119 patients en hémorragie active (93\%). Le saignement est réapparu dans 75 cas ( $23 \%$ ), avec un intervalle de temps moyen

Department of Gastroenterology and Division of General and Digestive Surgery, Hospital de la Santa Creu i Sant Pau, Barcelona, Spain

Correspondence and reprints: Dr Joaquim Balanzó, Servei de Patologia Digestive, Hospital de La Santa Creu i Sant Pau, Avgda.Sant Antoni M Claret, 167.08025. Barcelona, Spain.

Telephone 34932364721 , Fax 3434560160

Received for publication April 29, 1992. Accepted May 11, 1992
$\mathrm{B}$ EEDING PEPTIC ULCER REMAINS A relevant health problem with significant morbidity and mortality despite the introduction of diagnostic endoscopy, improvements in technology for resuscitation of bleeding patients and in medical management of ulcers with pharmacological agents (1). However, diagnostic endoscopy has assumed an important role due to its accuracy in detecting the bleeding lesions and in defining stigmata of recent hemorrhage which are valuable prognostic indicators of the risk of an unfavorable outcome (2). Furthermore, from the results of the controlled studies reported to date $(3,4)$ and the conclusions of the Consensus Conference at the USA National Institutes of Health (NIH) (5), therapeutic endoscopy can be regarded as the first hemostatic procedure in patients with ulcers at high risk of further bleeding.

A recent meta-analysis also showed that therapeutic endoscopy reduces rebleeding and requirement for emergency surgery by nearly two-thirds and mortality by nearly one-third (4). Patients with clinical evidence of a major hemorrhage and active arterial bleeding or a nonbleeding visible vessel at endoscopy should be treated (5). The $\mathrm{NIH}$ Consensus Conference deter- 
de $53 \pm 52$ heures. Une deuxième injection d'urgence a été administrée dans 36 des cas où la manoeuvre a échoué et a réussi chez 20 d'entre eux (55\%). Une chirurgie d'urgence a finalement été nécessaire dans 52 cas (15\%). Le taux de mortalité globale a été de 4,9\%. De graves complications se sont produites chez 4 patients $(1,2 \%)$. (Il s'agissait de deux cas de perforation et de deux cas de pneumonie par inhalation.) On peut donc conclure que le traitement par injection est une méthode efficace et simple de traiter les ulcères actifs pour parvenir à maîtriser rapidement l'hémorragie dans la majorité des cas, bien que le taux de récurrence de l'hémorragie et des complications ne soit pas négligeable.

mined that multipolar electrocoagulation and heat probe were the most promising techniques and that injection therapy warranted further study. In the past few years several prospective and controlled trials have shown the efficacy of injection therapy (6-12), its simplicity, safety and low cost are great advantages. Comparative studies have also shown that its efficacy seems to be equal to that of thermal methods such as YAG laser (12) or multipolar electrocoagulation (13), while similar or inferior results have been achieved compared with heat probes $(14,15)$.

The present report describes the results achieved with injection therapy in a large series of patients admitted consecutively with a bleeding peptic ulcer at high risk of further hemorrhage, assessed by the presence of active arterial bleeding, or a nonbleeding visible vessel. Some technical variations such as the use of a second emergency injection in the management of therapeutic failures were also evaluated.

\section{PATIENTS AND METHODS}

During a 42-month period (1987. 91), 1880 patients were admitted to the authors' hospital because of confirmed upper gastrointestinal hemorrhage. Emergency endoscopy was performed in all within $4 \mathrm{~h}$ of admission, after resuscitation measures and lavage by nasogastric tube. Endoscopy disclosed 341 patients with gastroduodenal ulcers and active arterial bleeding or a nonbleeding visible vessel. Injection therapy was performed in all of these patients. No patient was excluded because of technical problems, the severity of bleeding or the location of the ulcer. No other selection criteria were used.
Emergency endoscopy was performed using an Olympus IT10 or IT20 fibrescope. Vigorous washing of the ulcer floor was carried out when required to remove clots and debris. Adrenaline injection was performed with a Microvasive 1123 needle (Massachusetts), during the same emergency procedure. Some patients were also included in two controlled trials to evaluate whether addition of thrombin (16) or $1 \%$ polidocanol (17) could improve the results achieved with adrenaline alone. Adrenaline $(1 / 10,000)$ was injected in aliquots of 1.0 to $2.0 \mathrm{~mL}$ first around and then into the visible vessel or over and around the bleeding area, up to a total of 10 to $15 \mathrm{~mL}$. After therapeutic endoscopy, all patients were admitted to the gastrointestinal bleeding unit.

Whenever possible a second elective endoscopy was performed between the second and the third day after the emergency procedure. When a visible vessel was identified at the time of this elective endoscopy, a second injection was carried out by the same method as described above.

Permanent hemostasis was defined as cessation of bleeding (initial hemostasis) and absence of recurrence during hospitalization. Treatment was considered a failure if there were signs of further bleeding after the emergency injection treatment. Further bleeding was defined as one of the following: active bleeding at repeated endoscopy; vomiting of fresh blood or bloody aspirates after previous clear lavages by nasogastric tube; or the passage of fresh melena, plus: hemodynamic and clinical evidence of hypovolemia; or a fall of hemoglobin requiring transfusion. Repeated endoscopy when therapeutic failure occurred was not mandated by the protocol and was only performed in case of doubt.

Student's $t$ test and the $\chi^{2}$ test with the Yates' correction when necessary, were used for statistical analysis. $\mathrm{P}<0.05$ was considered statistically significant. Continuous variables were expressed as mean \pm one standard deviation.

\section{RESULTS}

Of the 341 patients included, there were 230 males and 111 females, with a mean age of $64.9 \pm 15$ years. The location of the ulcer was gastric in 110 cases $(32.3 \%)$, duodenal in $198(58 \%)$, pyloric in $16(4.7 \%)$ and stomal in 17 $(5 \%)$. Active spurting bleeding was disclosed in 12 patients $(3.5 \%)$, oozing in $107(31.4 \%)$ and a nonbleeding visible vessel in the remaining $222(65.1 \%)$. In 137 patients there was associated chronic disease $(40.2 \%)$.

Initial hemostasis was achieved in 111 of the 119 patients with active bleeding (93\%). Only in two patients was injection therapy impossible due to ongoing hemorrhage with hemodynamic instability in both cases. Emergency surgery was performed in six of eight patients with persistent bleeding, and definitive hemostasis was achieved. The remaining two patients died without further hemostatic treatment.

Rebleeding occurred in 75 of the 333 patients in whom the hemorrhage had been controlled initially $(22 \%)$ at a mean of $53 \pm 52 \mathrm{~h}$. In 30 of these patients emergency surgery was performed (one death). In 36 rebleeders a second endoscopic injection was attempted and was successful in 20 cases $(55 \%)$, but emergency surgery was required in 15 (one death). Another patient died without surgery after the failure of the second emergency injection. In the remaining nine rebleeders no further treatment was attempted, due to the gravity of associated diseases. Rebleeding was self-limited in two and the other seven died.

Four major complications resulted from the injection technique $(1.2 \%)$, two perforations (one death after surgery) and two aspiration pneumonia (one death). No adverse systemic ef- 
TABLE 1

Global results of endoscopic injection therapy in 341 patients

\begin{tabular}{lc}
\hline Results & Number (\%) \\
\hline Initial hemostasis & $333(97 \%)$ \\
Rebleeding & $75 / 333(22 \%)$ \\
Emergency surgery & $52(15 \%)$ \\
Major complications & $4(1.2 \%)$ \\
Mortality & $17(4.9 \%)$ \\
"Transfusion (mean \pm SD) & $2.7 \pm 2.7$ \\
Hospital stay (days, & \\
mean \pm SD) & $10.9 \pm 9.9$ \\
\hline
\end{tabular}

Units of packed red cells

fects in relation to the injected agents were observed.

Emergency surgery was required in 52 patients $(15 \%)$, in 51 because of uncontrolled hemorrhage and in one due to a complication of the technique. Injection therapy was successful in 258 patients after one emergency injection $(75.6 \%)$ while permanent hemostasis was finally achieved in 278 cases $(81.5 \%)$. Transfusional requirements were $2.7 \pm 2.7$ units of packed red blood cells and the duration of the hospital stay was 10.9 \pm 9.9 days (Table 1).

Overall mortality was 17 patients $(4.9 \%)$ due to the hemorrhage or related to procedural complications in 12 cases $(3.5 \%)$. The remaining five patients died from associated diseases after definitive control of the hemorrhage.

Results were also evaluated according to the stigmata of hemorrhage observed at the time of the initial emergency endoscopy (Table 2). Patients with a nonbleeding visible vessel had a tendency towards lower rates of therapeutic failure, fewer needs for emergency surgery, lower transfusional requirements and a shorter length of hospital stay although none of the trends reached statistical significance.

The results were also analyzed according to the location of the ulcer in regard to large vessels. Therapeutic failures were significantly more common in ulcers located in the posterior wall of the duodenal bulb ( 24 of 48 , $50 \%$ ) than in those at other sites $(\mathrm{P}<0.05)$. Therapeutic failures were no more frequent in ulcers located at the inferior wall of the bulb (zero of 10) or high in the lesser gastric curvature (five of $19,26 \%$ ).

TABLE 2

Results of endoscopic injection therapy in 341 patients according to the stigmata of hemorrhage disclosed at admission

\begin{tabular}{lcc}
\hline Results & $\begin{array}{c}\text { Active bleeding } \\
(n=119)\end{array}$ & $\begin{array}{c}\text { Nonbleeding visible } \\
\text { vessel }(n=222)\end{array}$ \\
\hline Therapeutic failure & $35(29 \%)$ & $48(22 \%)$ \\
Emergency surgery & $23(19 \%)$ & $30(14 \%)$ \\
*Transfusion (mean \pm SD) & $3.1 \pm 3.4$ & $2.5 \pm 2.4$ \\
Hospital stay (days, mean \pm SD) & $11.7 \pm 9.9$ & $10.7 \pm 9.8$ \\
Mortality & $7(5 \%)$ & $10(5 \%)$ \\
Time of rebleeding $(h$, mean \pm SD) & $64.9 \pm 61.7$ & $44.1 \pm 53.1$ \\
\hline
\end{tabular}

*Units of packed red cells. No significant differences between two groups

\section{DISCUSSION}

Further hemorrhage is the single most important prognostic factor for patients with a bleeding ulcer (18). The presence of active arterial bleeding at emergency endoscopy is associated with further hemorrhage in $85 \%$ of cases (2), while a nonbleeding visible vessel on the ulcer floor results in a rebleeding rate of 35 to $55 \%$ (2). Stigmata of bleeding also provide a target to which endoscopic therapy must be addressed to obliterate the underlying artery $(19,20)$. In the present study, all patients in whom emergency endoscopy disclosed stigmata of hemorrhage received injection therapy. The procedure could be performed in all but two of the 341 cases $(0.6 \%)$ because of exsanguinating hemorrhage. Initial hemostasis was achieved in 93\% of cases and permanent hemostasis in $81.5 \%$, while emergency surgery was required in $15 \%$, with an overall mortality of only $5 \%$.

A previous controlled trial had similar rates of efficacy using injection therapy in a selected high risk population (6). The results achieved in other controlled trials evaluating injection therapy have been similar (7-12) and have been confirmed by a recent metaanalysis (4). However, in only one of these trials was mortality significantly improved (9).

There were four severe complications $(1.2 \%)$ in the present study, with two deaths, indicating that despite the safety of the technique the rate of complications is not irrelevant. Thus, as suggested by the NIH Consensus Conference (5), correct indication, careful performance of injections and close monitoring of patients are mandatory to improve safety.

The present results indicated that there was a tendency towards better results in patients injected with a nonbleeding visible vessel compared with patients with active arterial bleeding, although the trend did not achieve statistical significance. In keeping with other authors (21-23), therapeutic failure was significantly more frequent in patients with ulcers at the posterior wall of the duodenal bulb, close to the gastroduodenal artery.

As in previous controlled trials (610), the initial control of hemorrhage was achieved in more than $90 \%$ of active bleeders, suggesting that most of the time surgery could be performed on hemodynamically stable patients.

The routine use of a second endoscopic treatment in the presence of failure must be considered with caution as it could increase the mortality by delaying surgery. In the present study surgery was performed as soon as evidence of rebleeding was elicited. only when a major surgical contraindication was present, a second endoscopic treatment was performed. This happened in 36 patients and bleeding was controlled in $22(53.6 \%)$ while the remaining required surgery. With this approach there was a very low total mortality (17 patients, $4.9 \%$ ); in only 12 cases was death related to the hemorrhage or to complications of treatment $(3.5 \%)$.

Few comparative studies have been performed to evaluate the most suitable solution for injection therapy. In previous controlled trials, the present authors assessed the efficacy of 
adrenaline alone or combined with either thrombin (15) or $1 \%$ polidocanol (16). Combined injections did not improve outcome.

Present results indicate that endoscopic injection of adrenaline is a simple and effective first therapeutic approach for bleeding peptic ulcers at risk of further hemorrhage. Major complications, although rare, are not ir-

\section{REFERENCES}

1. Gilbert DA. Epidemiology of upper gastrointestinal bleeding. Gastrointest Endose 1990;36:S8-13.

2. Johnston JH. Endoscopic risk factors for bleeding peptic ulcer. Gastrointest Endose 1990;36:S16-20.

3. Henry DA, White I. Endoscopic coagulation for gastrointestinal bleeding. N Engl J Med 1988;318:186-7.

4. Sacks HS, Chalmers TC, Blum AL, Berrier J, Pagano D. Endoscopic hemostasis. An effective therapy for bleeding peptic ulcers. JAMA 1990;264:494-9.

5. Proceedings of the Consensus Conference. Therapeutic endoscopy and bleeding ulcers: NIH Consensus Conference. JAMA 1989;262:1369-72.

6. Balanzó J, Sáinz S, Such J, et al. Endoscopic hemostasis by local injection of epinephrine and polidocanol in bleeding ulcer. A prospective randomized trial. Endoscopy 1988;20:289-91.

7. Panés J, Viver J, Forné M, GarciaOlivares E, Marco C, Garau J. Controlled trial of endoscopic sclerosis in bleeding peptic ulcers. Lancet 1987;ii: 1292-4.

8. Chung SCS, Leung JWC, Steele RJC, Crofts TJ, Li AKC. Endoscopic injection of adrenaline for actively bleeding ulcers:a randomized trial. Br Med J 1988:296:1631-3.

9. Pascu O, Dräghici A, Acalouchi I. The effect of endoscopic hemostasis with alcohol on the mortality rate of relevant. With endoscopic injection, initial hemostasis can be achieved in a majority of cases. However, the incidence of further hemorrhage is not negligible, as with any other method of therapeutic endoscopy. The present study shows that rebleeding occurs early (at a mean time of $53 \mathrm{~h}$ ). Further randomized and controlled trials are required to evaluate whether perfor-

nonvariceal upper gastrointestinal hemorrhage. Endoscopy 1989;21:53-5.

10. Rajgopal C, Palmer KR. Endoscopic injection sclerosis: Effective treatment for bleeding ulcer. Gut 1991;32:727-9.

11. Chiozzini G, Bortoluzzi F, Pallini P, et al. Controlled trial of absolute ethanol versus epinephrine as injection agent in gastroduodenal bleeding. Gastroenterology 1989;96:A86. (Abst)

12. Rutgeerts P, Vantrapen G, Broeckaert L, Coremans G, Janssens J, Hiele M. Comparison of endoscopic polidocanol injection and Yag laser therapy for bleeding paptic ulcers. Lancet 1989; i:1164-7.

13. Laine L. Multipolar electrocoagulation versus injection therapy in the treatment of bleeding paptic ulcers. A prospective randomized trial. Gastroenterology 1990;99:1303-6.

14. Lin HL, Tsai YT, Lee SD, et al. A prospective randomized trial of heat probe thermocoagulation versus pure alcohol injection in nonvariceal peptic ulcer hemorrhage. Am J Gastroenterol 1989;83:283-6.

15. Chung SCS, Leung JWC, Sung JY, Lo $\mathrm{KK}, \mathrm{Li} \mathrm{AKC}$. Injection or heat probe for bleeding ulcer. Gastroenterology 1991;100:33-7.

16. Balanzó J, Villanueva C, Sáinz S, et al. Injection therapy of bleeding paptic ulcer. A prospective, randomized trial using adrenaline and thrombin. Endoscopy 1990;22:157-9.

17. Balanzó J, Villanueva C, Sáinz S, et al. Injection therapy in bleeding paptic ulcer in a prospective randomized trial mance of a second early elective treatment after the initial control of hemorrhage by injection could improve results by avoiding rebleeding $(16,24,25)$. The present authors advise surgery in the presence of therapeutic failure, except when there are major contraindications. With this approach they achieved a very low mortality rate $(4.9 \%)$.

using epinephrine vs epinephrine and aetoxisclerol. Presented at the World Congress of Gastroenterology, 1990.

18. De Dombal FT, Clarke JR, Clamp SE, Malizia G, Kotwal MR, Morgan AG.

Prognostic factors in upper GI bleeding. Endoscopy 1986;18(Suppl 2); 18:6-10.

19. Swain CP, Storey DW, Bown SG, et al. Nature of the bleeding vessel in recurrently bleeding gastric ulcers. Gastroenterology 1986;90:595-608.

20. Swain CP. Pathophysiology of bleeding lesions. Gastrointest Endosc 1990;36:S21-2.

21. Swain CP, Salmon PR, Northfield TC. Does ulcer position influence presentation or prognosis of upper gastrointestinal bleeding? Gut 1986;27:A632.

22. Brullet E, Campo R, Bedos G, Barcons S, Gubern JM, Bordas JM. Site and size of bleeding paptic ulcer. Is there any relation to the efficacy of hemostatic sclerotherapy? Endoscopy 1991;23:73-5.

23. Steele RJC, ParK KGM, Crofts TJ. Adrenaline injection for endoscopic haemostasis in non-variceal upper gastrointestinal haemorrhage. $\mathrm{Br} J$ Surg 1991;78:477-9.

24. Pimpl W, Boeckl O, Heinerman M, Daupunt O. Emergency endoscopy: A basis for therapeutic decisions in the treatment of severe gastroduodenal bleeding. World J Surg 1989;13:592-7.

25. Steele RJC. Endoscopic haemostasis for non-variceal upper gastrointestinal hemorrhage. Br J Surg 1989;76:219-25. 


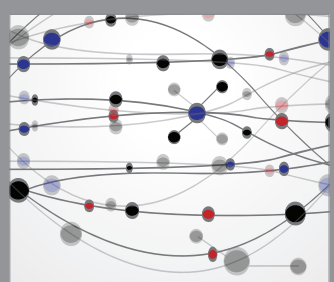

The Scientific World Journal
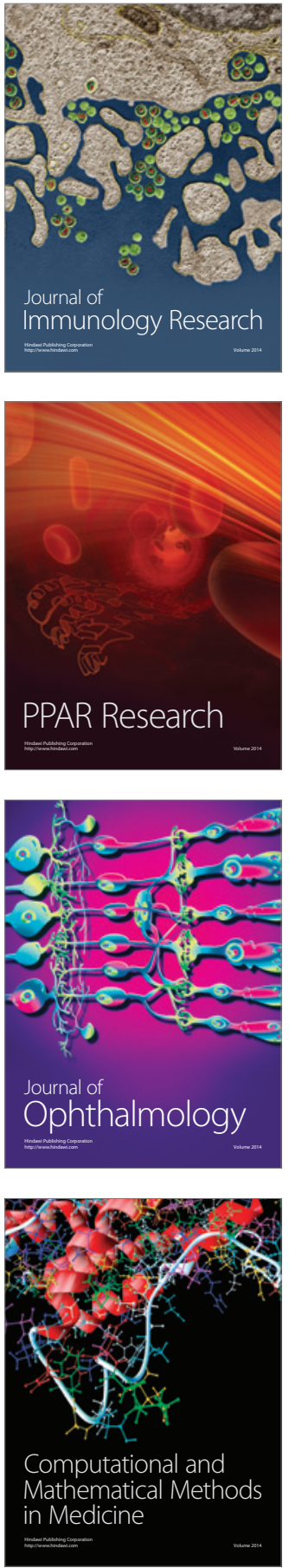

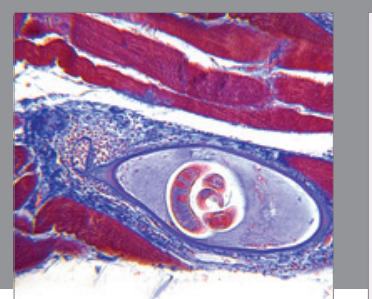

Gastroenterology Research and Practice

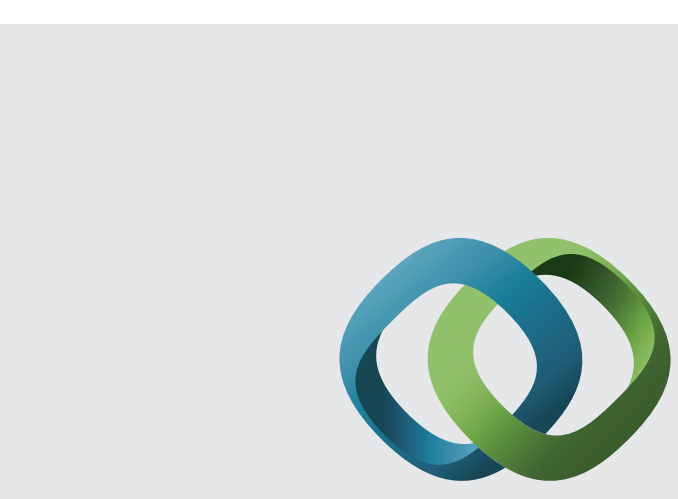

\section{Hindawi}

Submit your manuscripts at

http://www.hindawi.com
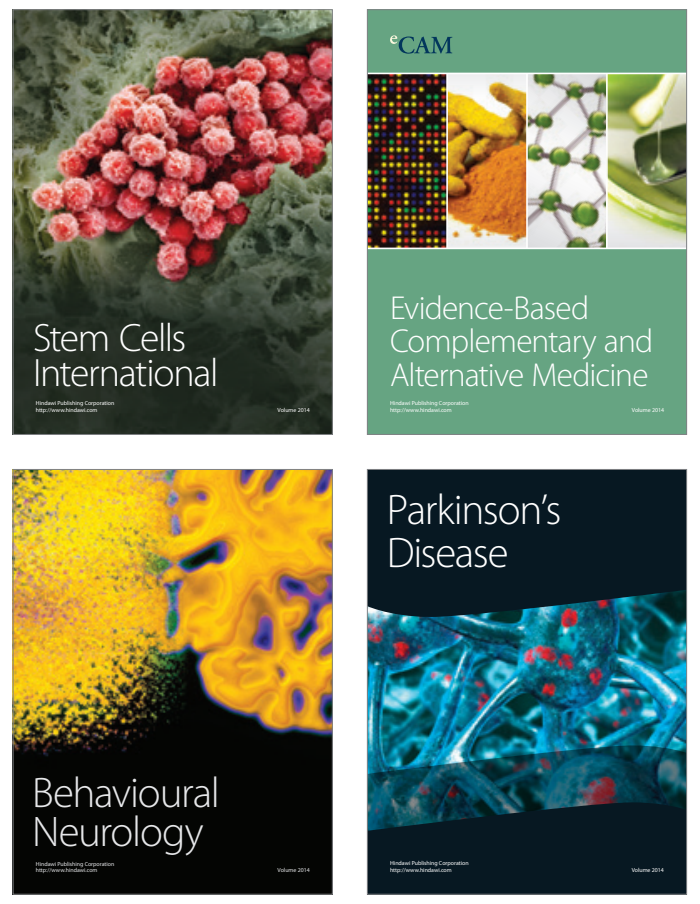
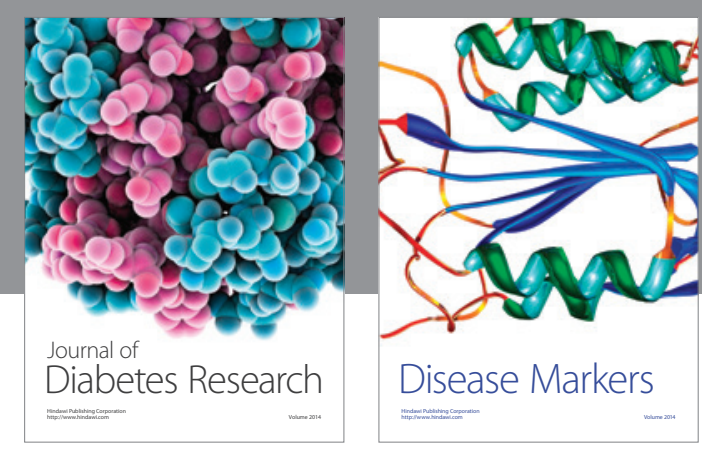

Disease Markers
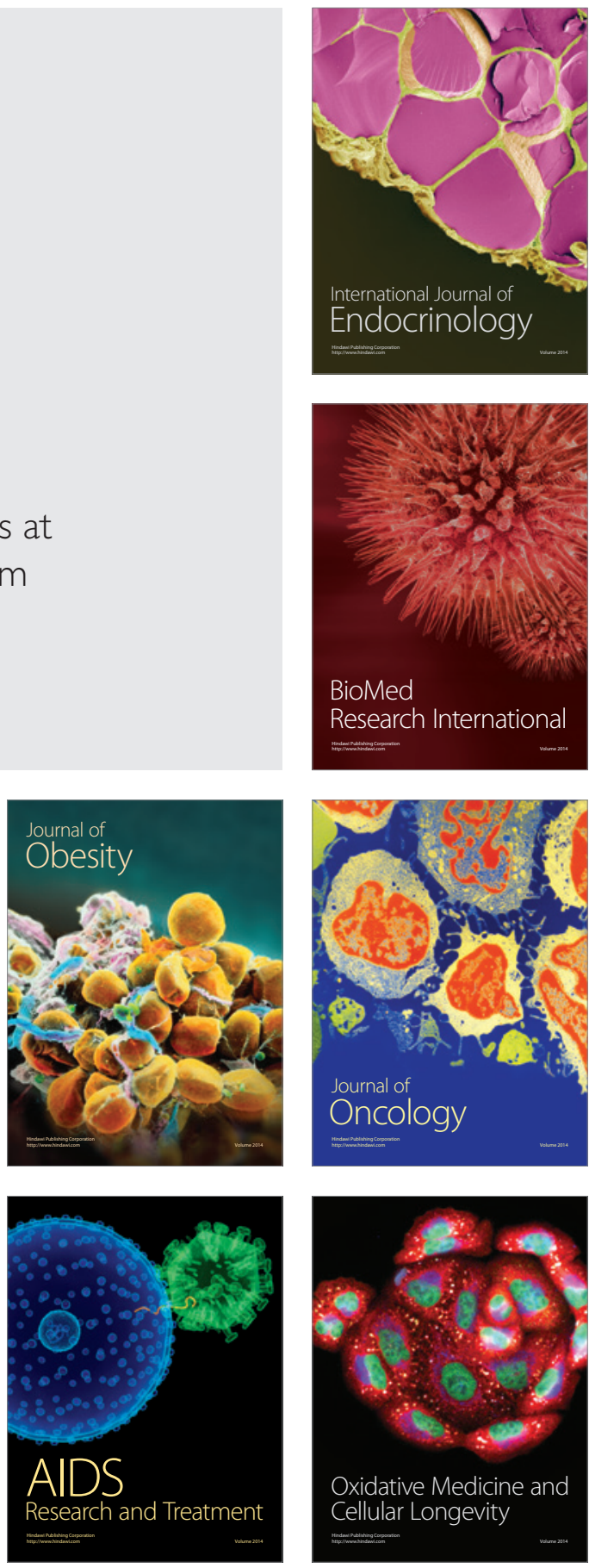